\title{
An exploration study to find important factors influencing on authenticity of brand
}

\author{
Naser Azad*, Elham Eghbali, Mehrnaz Moshkelati, Hamid Bagheri and Hamed Asgari
}

Department of Management, Islamic Azad University, South Tehran Branch, Tehran, Iran

\begin{tabular}{l}
\hline C H R O N I C L E \\
\hline Article history: \\
Received May 12, 2013 \\
Received in revised format \\
12 August 2013 \\
Accepted 14 August 2013 \\
Available online \\
August 15 2013 \\
\hline Keywords: \\
Brand identification \\
Factor analysis \\
Authenticity of brand
\end{tabular}
A B S T R A C T

\begin{abstract}
Building an appropriate brand always makes it possible to reach better market share in competitive market. This paper presents a study to find important factors influencing the authenticity of brand. The proposed study designs a questionnaire in Likert scale consists of 21 questions, distributes it among 400 people who purchase regularly from chain stores in city of Tehran, Iran and collects 388 filled ones. Cronbach alpha is calculated as 0.712. In addition, Kaiser-Meyer-Olkin Measure of Sampling Adequacy and Approx. Chi-Square are 0.748 and 1718.212, respectively. Based on the results of our survey, we have derived five factors including brand identification, brand registration, brand position, perception image from the brand and trust to brand.
\end{abstract}

\section{Introduction}

Brand plays an essential role for the success of all organizations and there are various studies on helping business owners build a good brand (MacCannell, 1973; Grant, 1999; Goulding, 2001; Brown et al., 2003). Abimbola and Vallaster (2007) gave a brief historical examination of brand, organization identity and reputation in small and medium-sized enterprises (SMEs). Ballantyne et al. (2006) traced some key developments in the evolution of consumer brand choice. They stated that today's consumer could be characterized as suffering from "over choice" and choice fatigue. Therefore, consumers have developed phased decision-making strategies in order to detect precise decision making. An integral component of these phased decision-making strategies was the formation of a downsized subset of brands, the consideration set, from which brand choice was made. They stated that brands must develop an emotional and symbolic attachment with consumers to succeed in today's highly competitive marketplace. Brand managers must understand that it is only through the manipulation and molding of brand image that truly meaningful differentiation and brand meaning could be accessed. They explained that brand image could be viewed as a multi-dimensional construct. Gupta *Corresponding author.

E-mail address:dr.naserazad@yahoo.com (N. Azad) 
et al. (2010) studied a one-to-one relationship for branding in business-to-business markets using some qualitative methods. They tried to clarify the links between branding, relationship marketing and purchase intention of resellers and explained the contribution of brand personified as brand representatives to the brand knowledge of resellers. They explained that the brand personified with its metaphorical properties enabled the resellers not only to clearly recognize brand-related information but also to make positive evaluations about the brand.

During the past few years, there are many studies associated on authenticity of brand on the market (Miranda, \& Klement, 2009). Beverland (2005) provided an overview of the challenges that the widespread desire for authenticity presents for brand managers. The study indicated that authenticity requires brand managers to downplay their overt marketing prowess and instead locate their brands within communities and sub-cultures. According to Leigh et al. (2006), authenticity in the consumption context plays essential role on the marketing literature. Beverland et al. (2008) investigated authenticity through advertising by studying consumer judgments of advertisers' claims. Beverland and Farrelly (2009) looked at the quest for authenticity in consumption by looking into consumers' purposive choice of authentic cues to shape experienced outcomes. Rose and Wood (2005) looked into the paradox and the consumption of authenticity through reality television. Grayson and Martinec (2004) investigated consumer perceptions of iconicity and indexicality and their influence on assessments of authentic market offerings. Chhabra (2005) determined authenticity and its determinants toward an authenticity flow model. Goulding (2000) studied the commodification of the past, postmodern pastiche, and the search for authentic experiences at contemporary heritage attractions.

According to Azad et al. (2013a) building a famous brand often makes it possible to have sustainable growth in competitive market. An appropriate brand name plays an important role on increasing word of mouth advertisement, the number of loyal customers and repurchase habits. Nevertheless, in order to construct a good brand, we need to build sustainable brand identification and to do this we need to determine influential factors. Azad et al. (2013a) presented an empirical investigation to detect important factors affecting brand identification. They derived five factors including sense of brand, brand community, trust to brand, value of brand and personality of brand. Azad et al. (2013b), in other study, detected important factors impacting on food market using factor analysis. They reported six major factors including brand loyalty, physical characteristics, pricing effects, performance characteristics, brand relationship and brand position influence food industry, significantly. Danaei et al. (2013) studied the effect of advertisements on customers' willingness to accept banking services based on modulatory role of brand. They analyzed the gathered data using structural equation modeling and the preliminary results indicated that there was a positive and meaningful relationship between brand advertisement and associate name and brand identification. However, there was no meaningful relationship between brand advertisement and customer loyalty towards to brand. In addition, the results of survey indicated there was a meaningful relationship between brand equity components including perception quality on brand name, customer awareness from brand, loyalty to brand and customers' willingness to accept banking services on modulatory role of brand.

\section{The proposed study}

This paper presents an empirical investigation to find important factors influencing authenticity of brand. The proposed study designs a questionnaire in Likert scale consists of 21 questions, distributes it among 400 people who purchase regularly from some chain stores in city of Tehran, Iran and collects 381 filled ones. Cronbach alpha is calculated as 0.712 .

In addition, Kaiser-Meyer-Olkin Measure of Sampling Adequacy and Approx. Chi-Square are 0.748 and 1718.212, respectively. Since we plan to factor analysis and this method is sensitive to skewness of the data we first look at some of the basic statistics including the skewness of the data, which are summarized in Table 1. As we can observe from the results of Table 1, all skewness data are within an acceptable limit and we do not need to remove any question from the survey. 
Table 1

The summary of basic descriptive statistics

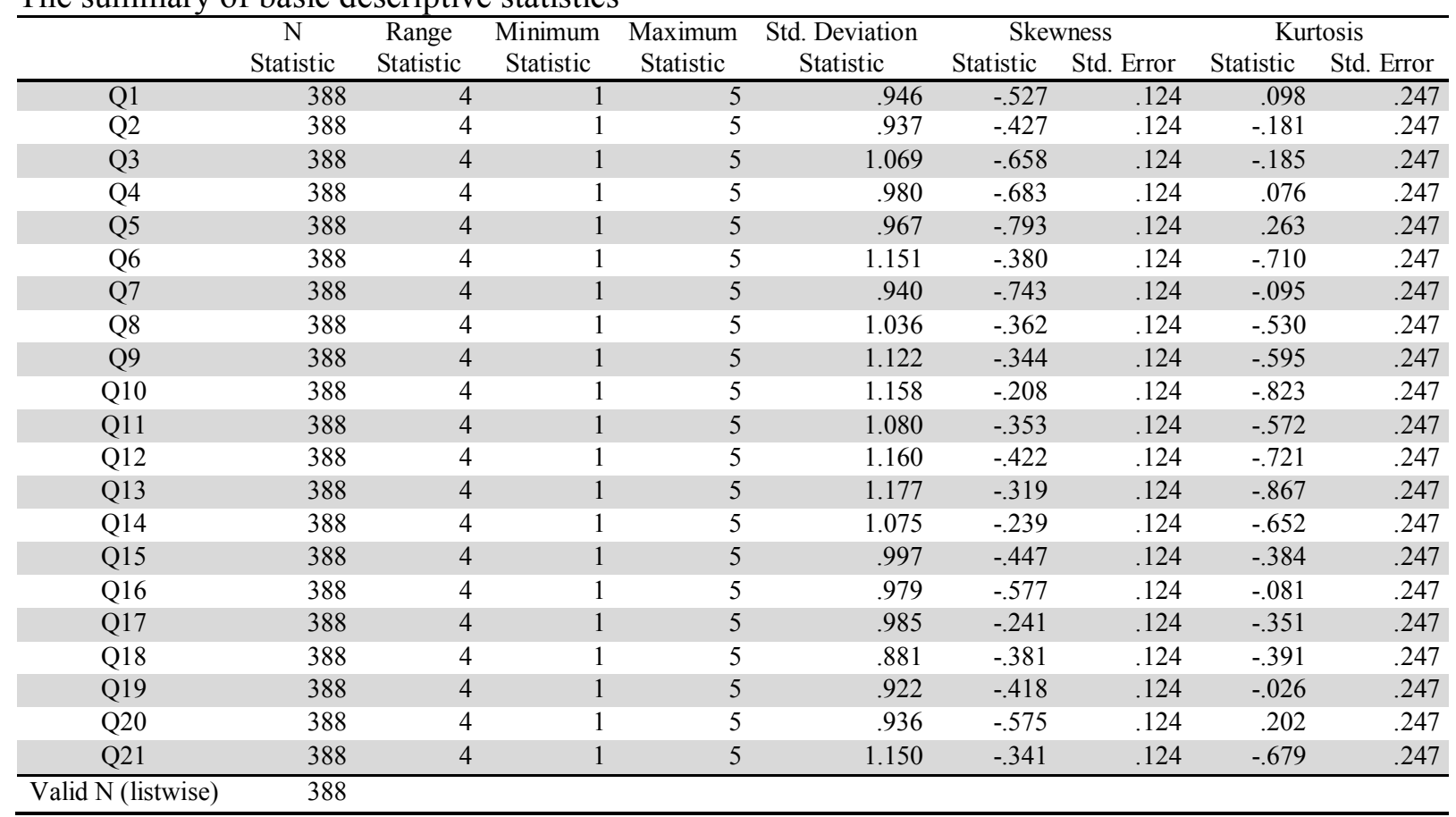

Table 2 demonstrates the results of factor analysis on these factors.

Table 2

The summary of principal component analysis after rotation

\begin{tabular}{|c|c|c|c|c|c|c|c|c|c|}
\hline \multirow[b]{2}{*}{ Component } & \multicolumn{3}{|c|}{ Initial Eigenvalues } & \multicolumn{3}{|c|}{ Extraction Sums of Squared Loadings } & \multicolumn{3}{|c|}{ Rotation Sums of Squared Loadings } \\
\hline & Total & $\%$ of Variance & Cumulative $\%$ & Total & $\%$ of Variance & Cumulative \% & Total & $\%$ of Variance & Cumulative \% \\
\hline 1 & 3.449 & 16.425 & 16.425 & 3.449 & 16.425 & 16.425 & 2.327 & 11.080 & 11.080 \\
\hline 2 & 2.541 & 12.102 & 28.527 & 2.541 & 12.102 & 28.527 & 2.286 & 10.886 & 21.966 \\
\hline 3 & 2.147 & 10.221 & 38.748 & 2.147 & 10.221 & 38.748 & 2.196 & 10.459 & 32.425 \\
\hline 4 & 1.445 & 6.882 & 45.630 & 1.445 & 6.882 & 45.630 & 1.930 & 9.192 & 41.617 \\
\hline 5 & 1.312 & 6.247 & 51.877 & 1.312 & 6.247 & 51.877 & 1.615 & 7.691 & 49.308 \\
\hline 6 & 1.041 & 4.957 & 56.834 & 1.041 & 4.957 & 56.834 & 1.580 & 7.526 & 56.834 \\
\hline 7 & .948 & 4.512 & 61.346 & & & & & & \\
\hline 8 & .835 & 3.976 & 65.323 & & & & & & \\
\hline 9 & .822 & 3.915 & 69.238 & & & & & & \\
\hline 10 & .724 & 3.446 & 72.684 & & & & & & \\
\hline 11 & .696 & 3.315 & 75.999 & & & & & & \\
\hline 12 & .638 & 3.038 & 79.037 & & & & & & \\
\hline 13 & .618 & 2.945 & 81.982 & & & & & & \\
\hline 14 & .575 & 2.736 & 84.718 & & & & & & \\
\hline 15 & .551 & 2.624 & 87.342 & & & & & & \\
\hline 16 & .518 & 2.467 & 89.809 & & & & & & \\
\hline 17 & .496 & 2.361 & 92.170 & & & & & & \\
\hline 18 & .465 & 2.213 & 94.384 & & & & & & \\
\hline 19 & .443 & 2.112 & 96.496 & & & & & & \\
\hline 20 & .409 & 1.949 & 98.445 & & & & & & \\
\hline 21 & .327 & 1.555 & 100.000 & & & & & & \\
\hline
\end{tabular}

In addition to the results of Table 2, we have looked at Scree plot to determine important factors and the results of figure and Table indicate that there were six factors. 


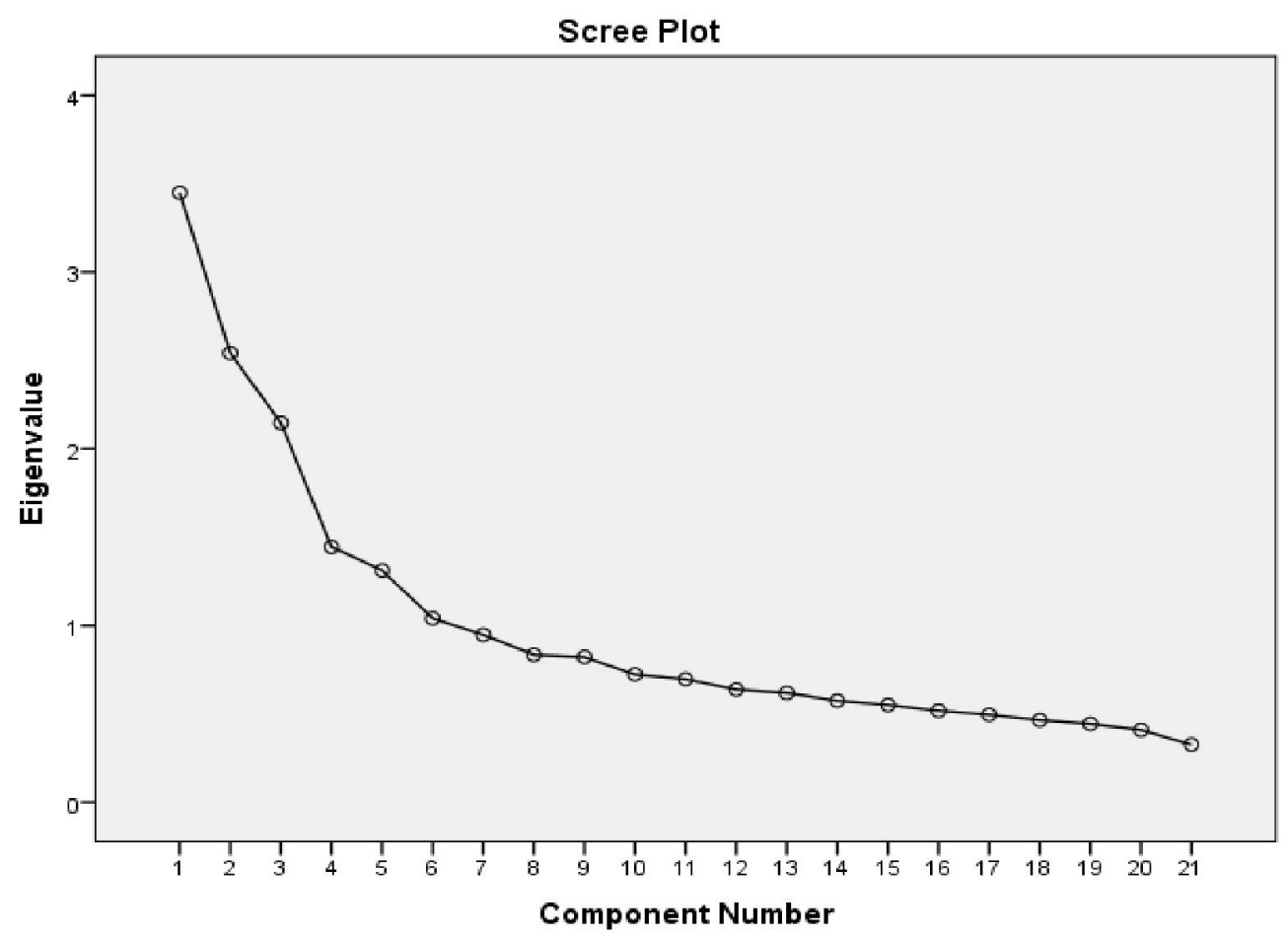

Fig. 1. The results of Scree plot

Based on the results of our survey, we have derived five factors including brand identification, brand registration, brand position, perception image from the brand and trust to brand summarized in Table 3 as follows,

\section{Table 3}

The summary of factor analysis

\begin{tabular}{|c|c|c|c|c|c|}
\hline Factor & Measurable variable & Weight & Eigenvalue & Variance & Accumulated \\
\hline \multirow{4}{*}{ Brand identification } & Theory of social identification & 0.813 & 2.327 & 11.08 & 11.08 \\
\hline & Organizational studies & 0.743 & & & \\
\hline & Credibility of trade mark & 0.725 & & & \\
\hline & Present values and normality & 0.531 & & & \\
\hline \multirow{6}{*}{ Brand registration } & Geographical relationships & 0.747 & 2.286 & 10.886 & 21.966 \\
\hline & Production method & 0.647 & & & \\
\hline & Registration of brand literally & 0.622 & & & \\
\hline & Organizational image & 0.586 & & & \\
\hline & Rational outlook & 0.433 & & & \\
\hline & Origin & 0.337 & & & \\
\hline \multirow[t]{3}{*}{ Brand position } & $\begin{array}{l}\text { Fluctuation in domestic and } \\
\text { foreign market }\end{array}$ & 0.741 & 2.196 & 10.459 & 32.325 \\
\hline & Customer position detection & 0.699 & & & \\
\hline & Qualitative commitments & 0.571 & & & \\
\hline \multirow{4}{*}{$\begin{array}{l}\text { Perception image } \\
\text { from the brand }\end{array}$} & Brand familiarity & 0.741 & 1.93 & 9.192 & 42.517 \\
\hline & $\begin{array}{l}\text { Awareness from the quality of } \\
\text { products }\end{array}$ & 0.699 & & & \\
\hline & Relationship & 0.571 & & & \\
\hline & Religious believes & 0.337 & & & \\
\hline \multirow[t]{2}{*}{ Trust to brand } & Being trustable & 0.789 & 1.615 & 7.691 & 50.178 \\
\hline & Brand loyalty & 0.604 & & & \\
\hline
\end{tabular}




\section{Discussion and conclusion}

This paper presented a study to find important factors influencing the authenticity of brand. The results of the survey have disclosed five influencing items including brand identification, brand registration, brand position, perception image from the brand and trust to brand. In terms of brand identification, Theory of social identification is believed to be the most important item followed by organizational studies, credibility of trademark and present values and normality. Brand registration is the second item in our survey, which includes six sub-components including Geographical relationships, production method, registration of brand literally, organizational image, rational outlook and origin. Brand position is the third item in our survey, which includes three subcomponents including fluctuation in domestic and foreign market, customer position detection and qualitative commitments. Perception image from the brand is the next influential factor, which includes four items including brand familiarity, awareness from the quality of products, relationship and religious believes. Trust to brandis the last influencing factor, which includes two items of being trustable and brand loyalty

\section{Acknowledgment}

The authors would like to thank the anonymous referees for their construction comments on earlier version of this work.

\section{References}

Abimbola, T., \& Vallaster, C. (2007). Brand, organisational identity and reputation in SMEs: an overview. Qualitative Market Research: An International Journal, 10(4), 341-348.

Azad, N., Seyedaliakbar, S.M., Hosseinzadeh, A., \& Arabi, A. (2013a). An exploration study on factors influencing Iranian food industry. Management Science Letters, 3(5), 1315-1322.

Azad, N., Raoof, D., Haj Seyed Javadi, S., Asgari, H., \& Bagheri, H. (2013b). An exploration study to find important factors influencing on brand identification. Management Science Letters, 3(9), 2425-2430.

Ballantyne, R., Warren, A., \& Nobbs, K. (2006). The evolution of brand choice. Journal of Brand Management, 13, 339-352.

Beverland, M. B. (2005). Brand management and the challenge of authenticity. Journal of Product and Brand Management, 14, 460-461.

Beverland, M. B., Lindgreen, A., \& Vink, M. (2008). Projecting authenticity through advertising: Consumer judgments of advertisers' claims. Journal of Advertising, 37, 5-15.

Beverland, M. B., \& Farrelly, F. J. (2009). The quest for authenticity in consumption: Consumers' purposive choice of authentic cues to shape experienced outcomes. Journal of Consumer Research, 36, 838-856.

Beverland, M. (2009). Building brand authenticity - 7 habits of iconic brands. New York: Palgrave Macmillan.

Brown, S., Kozinets, R. V., \& Sherry Jr, J. F. (2003). Teaching old brands new tricks: retro branding and the revival of brand meaning. Journal of Marketing, 19-33.

Danaei, A., Jahan, A., \& Saeidfar, M. (2013). A study on the effect of advertisements on customers' willingness to accept banking services based on modulatory role of brand: A case study of Bank Parsian. Management Science Letters, 3(5), 1439-1444.

Chhabra, D. (2005). Defining authenticity and its determinants toward an authenticity flow model. Journal of Travel Research, 44, 64-73.

Goulding, C. (2000). The commodification of the past, postmodern pastiche, and the search for authentic experiences at contemporary heritage attractions. European Journal of Marketing, 34, $835-853$. 
Goulding, C. (2001). Romancing the past: Heritage visiting and the nostalgic consumer. Psychology and Marketing, 18, 565-592.

Grayson, K., \& Martinec, R. (2004). Consumer perceptions of iconicity and indexicality and their influence on assessments of authentic market offerings. Journal of Consumer Research, 31, 296312.

Grant, J. (1999). The new marketing manifesto. London: Texere.

Gupta, S., Melewar, T. C., \& Bourlakis, M. (2010). Transfer of brand knowledge in business-tobusiness markets: A qualitative study. Journal of Business \& Industrial Marketing, 25, 395-403.

Leigh, T. W., Peters, C., \& Shelton, J. (2006). The consumer quest for authenticity: The multiplicity of meanings within the MG subculture of consumption. Journal of Academy of Marketing Science, 34, 481-493.

MacCannell, D. (1973). Staged authenticity: Arrangements of social space in tourist settings. American Journal of Sociology, 79, 589-603.

Miranda, R., \& Klement, J. (2009). Authentic trust in modern business. Journal of Wealth Management Spring, 11, 29-47.

Rose, R. L., \& Wood, S. L. (2005). Paradox and the consumption of authenticity through reality television. Journal of Consumer Research, 32, 284-296. 